\title{
2 The People Living with HIV STIGMASurvey UK 2015: Stigmatising experiences and dental care
}

3 Author(s): *Sandra OKALA ${ }^{1,2}$ *Janine DOUGHTY ${ }^{3}$, Richard G WATT ${ }^{3}$, Anthony SANTELLA ${ }^{6}$, David CONWAY ${ }^{7}$, Whitney CRENNA-JENNINGS ${ }^{1}$, Rebecca MBEWE ${ }^{4}$, Jackie MORTON ${ }^{4,5}$, Irina LUT ${ }^{1}$, Lisa THORLEY ${ }^{1,4}$ Lorna BENTON ${ }^{1}$, Matthew HIBBERT ${ }^{2}$, Jo JEFFERIES ${ }^{2}$, Christabel KUNDA ${ }^{4}$, Sheila MORRIS $^{5}$, Kevin OSBORNE ${ }^{4,9}$, Helena PATTERSON ${ }^{7}$, Laura SHARP ${ }^{1,7}$, George VALIOTIS ${ }^{8}$, Alastair HUDSON ${ }^{1,4}$ Valerie DELPECH $^{2,4}$

Institute(s): ${ }^{1}$ Family Planning Association, London, UK, ${ }^{2}$ Public Health England, London, UK, ${ }^{3}$ Research Department of Epidemiology \& Public Health, University College London, ${ }^{4}$ The People Living with HIV Stigma Index UK 2015 Advisory Group, London, UK, ${ }^{5}$ European AIDS Treatment Group (EATG), ${ }^{6}$ Hofstra University, ${ }^{7}$ Glasgow University, Glasgow, UK, ${ }^{8}$ HIV Scotland, Edinburgh, UK, ${ }^{9}$ The International AIDS Society (IAS)

*Lead authors

- Over $95 \%$ of the 85,000 people living with diagnosed HIV in the UK are achieving and maintaining an undetectable viral load whilst on effective antiretroviral therapy - they can expect a normal life span and are protected from transmitting HIV. Nevertheless people living with HIV reported high rates of stigma and discrimination when attending their dental practice in the previous 12 months.

- These findings are a wakeup call to the dental team to ensure that care is delivered without discrimination and prejudice.

- Greater awareness and training is required to ensure the dental team provides optimal care to people living with HIV in a supportive environment. 


\section{Abstract (200 words max for BDJ) \\ Introduction}

We report experiences of stigma and discrimination in the dental setting among people living with HIV in the UK and explore predictors of self-exclusion from dental care.

\section{Methods}

A convenient sample of people living with HIV recruited through community organisations and HIV clinics using an online anonymous survey. Analyses and writing of the findings were conducted with community engagement throughout.

\section{Results}

$53 \%$ of 1528 participants reported that their dental practice was aware of their HIV status, and among these $33 \%$ felt poorly supported upon disclosure. Over the previous 12 months, $40 \%$ had worried about being treated differently and $15 \%$ reported being treated differently to other people attending the dental practice; $5.4 \%$ felt their dental care was significantly delayed or refused and $14 \%$ had avoided their dental practice in relation to their HIV. Delayed or refused dental care was a strong predictor for self- exclusion (aOR=6.41, 95\%Cl:3.44,11.95)

\section{Conclusion}

People living with HIV continue to report high levels of stigmatising and discriminatory attitudes and behaviour in dental setting. These experiences were strongly associated with people avoiding dental care. Culturally sensitive awareness and educational tools targeting the dental team should be developed to address the stigma around HIV in this clinical setting.

(Abstract 200 max) 
Good oral health is important for overall health and wellbeing; particularly for those living with HIV. People living with HIV (PLHIV) have poorer oral health and greater dental care needs than the general population ${ }^{1}$. Oral conditions associated with HIV can impact on the ability to take medications, to maintain appropriate nutrition and subsequently lead to diminished physical health ${ }^{2-5}$. Dentists and other oral health care professionals have a role to play in the detection of oral complications associated with HIV and the onward referral of these patients to appropriate sexual health services ${ }^{6}$. Additionally, there is emergent evidence in support of the dental setting as an appropriate site to screen for HIV using oral fluid or capillary blood point-of-care testing ${ }^{6}$.

The use of antiretroviral therapy (ART) has extended the life expectancy of people living with HIV to the same level as the general population and HIV infection has moved from being considered as a deadly illness to a chronic disease ${ }^{7,8}$. Almost all (94\%) of the 85,000 people living with diagnosed HIV in the UK are on ART - they can expect a normal life span and are protected from transmitting HIV ${ }^{9}$. However, despite these, the stigma around HIV remains a major challenge for some PLHIV, negatively impacting upon their lives, health and wellbeing 10-12. Stigma has been defined as beliefs and attitudes that lead people to fear, avoid or reject those they perceive as being different ${ }^{13}$. Perceptions of stigma have been linked to barriers to testing, disclosure of HIV status and delays in seeking care ${ }^{10} 12$ 14-16. In 2008, PLHIV (N=241) recruited at a London genitourinary medicine clinic were significantly more likely to report difficulties when trying to register with a dentist compared to other patients (59\% vs $18 \%$ ); $35 \%$ reported that awareness of their HIV status in the dental setting had negatively impacted on the care received with $6.2 \%$ having been refused dental treatment ${ }^{17}$.

Over the last few decades changes in anti-discrimination laws have increased and protected the rights of PLHIV in the UK. Notably, the Equality Act 2010 , which replaced the Disability Discrimination Act 1995, and other anti-discrimination legislations designed to protect PLHIV from discrimination in various settings including in healthcare services ${ }^{18}$. Furthermore, the Department of Health and the British Dental Association recommend that universal cross infection control precautions are used for all patients irrespective of their HIV status. Evidence from smaller studies suggests that in the ART era, HIV-related stigma and discrimination continue within healthcare services including in the dental setting 11171920 . We aimed to assess the current experiences of PLHIV when attending dental services in the UK, and to examine the factors associated with accessing dental care in this population. 
The People Living with HIV Stigma Survey UK 2015 was a convenience sample of PLHIV aged 18 or older recruited by community members from 120 community organisations and at 47 HIV clinics. Participants' responses were stored securely and analysed at Public Health England (PHE) in accordance with the Data Protection Act 1998 with community engagement throughout. The study was reviewed and approved by the Brighton and Sussex Research Ethics Committee (IRAS ID: 160361).

\section{Questionnaire data}

The online anonymous survey contained questions about current feelings and experiences of HIV-related stigma in healthcare settings including dental practice, general practice (GP), genitourinary medicine (GUM) clinics, as well as inpatient and outpatient clinics. Respondents ranked the level of support that they received upon HIV disclosure between 0 and 100, and an arbitrary cut-off of 75 was used to distinguished between low and high level of support. Additionally, 10 questions were included about positive and negative feelings related to HIV in the last 12 months including: having felt positive about the future, in control of health, shame, guilt, and self-blame, some of which overlap with the Beck Depression Inventory ${ }^{21}$ (Fig 1). A 'self-image' composite score was created based on nine statements (excluding suicidal ideation): a "yes" or "not sure" answer to a question about positive feelings was given a value of 1 and 0.5 respectively, and a "yes" or "not sure" answer to a question about negative feelings a value of -1 and -0.5 . Composite scores ranged from -4 to 5 and a self-image score of -1 or less was assigned as "poor" with sensitivity analyses performed using different cut-offs.

\section{Statistical analysis}

97 Descriptive and analytical analyses were performed in Statav13 (StataCorp LLC, USA).Chi-squared test was used to compare the experiences of participants 98 by sociodemographic characteristics. Univariate and multivariate logistic regression analyses were conducted to determine the factors associated with selfexclusion of dental care. 


\section{Sociodemographic data}

Sociodemographic and clinical characteristics of the 1528 (97\%) participants who completed the health care setting are presented in Table 1. Three-quarters were men and almost two-thirds were men who have sex with men (MSM). The mean age was 44 years (95\% $\mathrm{Cl} 43.7-44.8$ years) with a 9 year median time since diagnosis (IQR=15-4 years). The majority of respondents were of White British ethnicity (60.4\%) followed by Black or Black British ethnicity (20.9\%). Financial hardship was common among respondents with 58.2\% "struggling "or "falling behind" with their bills. In line with the national average of the UK population living with HIV (94\%) PHE, 2016), 94.3\% of respondents were receiving ART. Just under half (45.2\%) of individuals had been diagnosed with a mental health condition; mainly depression (89\%) and a third (36.4\%) had a poor self-image in relation to their HIV (Table1, Fig 1).

\section{Disclosure of HIV status}

About half (53\%) of participants reported that their dental practice was aware of their HIV status $(53.3 \%)$ and this proportion increased with both the respondent's age and time since HIV diagnosis. Participants of Asian and Black ethnicity were less likely to have made their dental practice aware about their HIV status compared to those of white British ethnicity ( $27.0 \%$ and $40.1 \%$ respectively, vs $56.6 \%$, both $P<0.001$ ); as were those not on ART ( $33.6 \%$ vs $55.0 \%$ for those on ART $P<0.001)$. Dental practices were more likely to be aware of the HIV status of respondents who had a disability than those without $(69.3 \%$ vs $48.5 \%$, $P<0.001)$. Following HIV disclosure, a third of participants $(32.8 \%)$ did not feel well supported by dental staff. Notably, respondents from a non-white ethnic group were significantly less likely to feel supported than those of White British ethnicity ( $42.5 \%$ vs $27.5 \%, P<0.001$ ), those who identified as transgender (47.1\% vs $30.5 \% P<0.001)$; heterosexual women compared to MSM (41.4\% vs $30.5 \%, P=0.002)$ and respondents who reported that they were struggling with their bills $(38.3 \%$ vs $25.5 \%, P<0.001)$.

In the past 12 months, $39.9 \%$ of participants had worried about being treated differently to other patients in dental practices and $14.6 \%$ reported that they had actually been treated differently. Respondents with a poor self-image were more likely to report having been treated differently to other patients in dental practices $(20 \%$ vs $11.5 \%, P<0.001)$.

Over one in twenty (5.5\%) respondents reported that they felt they had been refused dental care or that it had been significantly delayed (Table 1). Markedly, participants from Black or Black British ethnic backgrounds were more likely to report this experience compared to White British respondents $(7.8 \%$ vs $4.7 \%$, 
$P=0.016)$ as did those who reported falling behind with their bills $(11.7 \%$ vs $3.0 \%, P<0.001)$ and those who identified as transgender $(21.9 \%$ vs $5.0, P<0.001)$. Almost all participants $(96.4 \%)$ who had felt refused or significantly delayed care by dental staff, reported that they worried about being treated differently in dental practices, compared to $38.1 \%$ who did not report this experience $(P<0.001)$. Furthermore, participants who had made dental staff aware of their HIV status were more than twice as likely to report being treated differently and feeling refused or significantly delayed dental care than those who had not disclosed their HIV status ( $19.5 \%$ vs $10.9 \%$ and $6.8 \%$ vs $3.2 \%$, respectively) (both, $P<0.001$ ).

\section{Factors associated with self-exclusion from dental practices among people living with HIV}

Of the 1528 participants, 1431 (93.7\%) indicated whether they had avoided seeking dental care when needed over the past 12 months (Table 2). In a multivariate model with adjustment for age, year of diagnosis, gender, financial commitments, self-image, feeling supported upon disclosure, worry about being treated differently, reported being treated differently and feeling refused or significantly delayed care; two factors stand out as being associated with self-exclusion from dental care. Participants who reported worry about being treated differently were nearly 8 times (adjusted Odds Ratio (aOR) $=7.52,95 \% \mathrm{Cl}: 4.80-11.76)$ more likely to avoid seeking dental care and those who felt refused or significantly delayed dental care were six times (aOR=6.41, 95\%Cl:3.44-11.95) more likely of having avoided seeking dental care within the past 12 months. Report of being treated differently ( $\mathrm{aOR}=2.89,95 \% \mathrm{Cl}: 1.86-4.47)$ and having a poor self-image $(\mathrm{aOR}=1.65,95 \% \mathrm{Cl}: 1.14-2.40)$ also remained independently associated with dental practice self-exclusion in the past 12 months (Table 2$)$.

\section{Perceptions of stigma in general and other healthcare settings.}

The study also explored experiences of stigma and discrimination in any health care setting as well as other specific settings. Overall $21 \%$ of respondents felt that excessive barrier protection was used in a healthcare settings over the past year, $12 \%$ had experienced their appointments being booked for the last slot in the day and $13 \%$ had experienced negative comments about their HIV in a healthcare setting. For those respondents who had attended for care in General Practice, General Dental Practice or at a Genitourinary Medicine (GUM) clinic (Figure 1). The report found that of those who provided responses about their experiences of stigma in dental practice, one-third (33\%) worried about being treated differently, in General Practice, the number reporting the same concern was one-quarter (27\%) of respondents and for those who received care in GUM clinics the figure was 1 in 20 (5\%). When asked about being treated differently in healthcare settings as a result of their HIV status, $15 \%$ of respondents agreed that this occurred in dental settings and $13 \%$ felt that this occurred in GP practices, contrastingly, only $3 \%$ felt treated different in the GUM setting. One in twenty (5\%) of the respondents felt that their treatment was refused or delayed 
as a result of their HIV status in dental and GP settings, whereas this figure was only $2 \%$ in a GUM clinic setting. In dental and general practice settings $14 \%$ of respondents had avoided seeking care as a result of perceptions of stigma related to their HIV status, almost five times more likely than avoiding care at a GUM clinic. Both dental settings and general practice showed considerably higher numbers of patients worried about being treated differently, reported being treated differently, felt refused or delayed treatment and avoided seeking care when compared with their experiences in a GUM clinic setting.

\section{Discussion}

The findings of this cross-sectional study indicate that in 2015, PLHIV continued to experience high levels of HIV-related stigma and discrimination when attending dental services in the UK, and that these experiences were strongly associated with self-exclusion from dental practices. Fear of being discriminated against in dental practices was strongly related to the actual experience of discrimination and one in twenty participants felt refused or significantly delayed dental care (in line with the findings from a smaller London study in $2008{ }^{17}$ ). Seven out of ten respondents who reported feeling refused or significantly delayed dental care indicated that they have avoided seeking care when needed in dental practices in the past year. Together, these findings suggest that stigma and discrimination experiences in dental practices are a source of anxiety for PLHIV and can directly impact on their oral and general health, through the refusal or delayed by dental staff in proving dental care for HIV patients. These discriminatory experiences may prevent PLHIV from seeking necessary dental care and thereby reduce their chance of achieving better oral and general health outcomes in addition to negative impacts on their mental health and wellbeing.

Similar to previous studies ${ }^{1722}$, about half of participants had made their dental practice aware of their HIV status. A third of those who had disclosed their HIV status felt poorly supported, and in particular, people from ethnic minority groups, transgender people, and those who struggle with their bills. Moreover, PLHIV were more likely to report being treated differently and feeling refused or significantly delayed dental care compared to those who did not discuss their HIV status. This indicates that lack of good support may discourage PLHIV from discussing their HIV status in the dental setting ${ }^{23}$. And as with previous studies, our study indicates that HIV-related stigma and discrimination in dental practices, is embedded with issues related to gender, ethnicity, sexual orientation, and socioeconomic inequalities ${ }^{15} 2324$.

Practices such as 'double-gloving' and scheduling dental appointments for the end of a treatment session for HIV patients are now considered archaic with universal precaution advice and guidance now accepted and applied routinely in dental practice ${ }^{25} 26$. However, the qualitative study of The People Living with HIV STIGMA Survey UK 2010 which interviewed 61 people indicated that PLHIV continue to experience such practices. Some of the participants explained that other people's negative experiences had made them anxious about disclosing their HIV in dental practices ${ }^{27}$. Furthermore, although the survey questions in 
our study did not specify the ways in which PLHIV felt that they had been treated differently in dental settings; a considerable proportion of participants felt that excessive barrier protection was used, had experienced their appointments being booked for the last slot in the day and reported experiences of negative comments about their HIV in a healthcare setting. These findings are echoed in the dental literature by a qualitative study undertaken in the United States which interviewed 66 PLHIV who revealed a variety of concerns related to receiving care in a dental setting ${ }^{11}$. Some of the participants were anxious that dentists would overreact to their condition by wearing double gloves or masks or that the dentist may be nervous to treat them or may discriminate against them. Despite double-gloving being described as an unnecessary practice when providing dental treatment almost two decades ago, dishearteningly these practices may still persist in general dental practice. For those who have been living with HIV for many years it is likely that they will have experienced attending dental settings during a time when such infection control practices were commonplace ${ }^{28}$. This may provide some explanation for the People Living with HIV STIGMASurvey UK 2015; results showed that respondents aged 35-49 were nearly twice as likely to report being treated differently to other patients in dental practices compared to those aged 25-34. This could be interpreted as a reflection of the changing attitudes of dental professionals and as a result, reduced experiences of stigma by those who are more recently diagnosed. It may also suggest that the respondents have reported an event experienced more than 12 months ago (recall bias) and this would skew the results toward a higher proportion of event being reported with increasing time to diagnosis (and potentially age).

In addition to the stigmatising clinical practices described above, perceptions of HIV stigma may be enhanced by the cost of dental care. In this study, $58.2 \%$ of respondents stated that they had difficulty keeping up with or were falling behind with paying bills. This may have been a prohibitive factor in accessing additional dental services such as attending a hygienist for private dental care or may have created an uneasy relationship with a dental practice if payment for dental care was delayed or outstanding. In General Dental Practice this could have had the potential to contribute to feelings of being treated differently due to HIV status. In the group of 217 respondents who reported to having avoided the dentist in the past year, $33.6 \%$ were not in full-time or part-time employment and $68.2 \%$ were struggling with or had fallen behind with bills.

Consistent with previous studies, the findings of this survey indicate that stigma around HIV in the dental setting continues to affect a significant proportion of people living with HIV.

\section{Strengths and weaknesses of the study}

This study was supported by an advisory group of academics, oral health experts including dentists, HIV experts and representatives of the HIV community. Nearly $2 \%$ of all the people living with HIV in the UK were enrolled across the country from 120 community organisations and 47 HIV clinics. The survey population was relatively representative of the population of PLHIV in the UK although the study aimed to include more participants from ethnic minority groups. 
The information collected was anonymous and securely collected online which provided an efficient platform for the disclosure of sensitive information. However, the experiences of stigma and discrimination were self-reported and may be biased by self-perception of stigma and discrimination, cultural differences between the different ethnic groups and other sociodemographic differences. Because this is a convenience sample, people with strong opinions about HIV stigma may have been more likely to be respond to the survey, thus giving a more marked perception of stigma in dental settings than truly exists. Furthermore, as it is a cross-sectional survey direct cause and effect relationship between experiences of stigma and discrimination in the dental setting and self-exclusion from seeking dental care could not be established but strong associations could be determined.

The findings of this study suggest that persisting perceptions of stigma and discrimination within the dental setting are significantly associated with self-exclusion from dental services and failure to receive dental treatment. The implications of such self-exclusion may be the unnecessary experience of preventable dental pain, a lack of opportunity for the delivery of oral health promotional education in a cohort known to have poorer oral health and potentially oral conditions that may be indicative of advancing HIV. Additionally, the findings have implications for the way in which dental care professionals provide services and treatment for PLHIV. Further undergraduate and postgraduate dental education may be of benefit, both to increase knowledge of Blood Borne Viruses (BBV) including HIV and to better prepare dental staff to manage disclosures of HIV status. Inclusion of cultural competency training may also serve to provide the next generation of dental staff with the tools to provide inclusive care to all vulnerable communities. Additional training and targeted Personal Development Plans may support dental staff to ensure that the care provided post-disclosure mirrors that provided for a patient who is not known to have HIV and that stigmatising clinical practices are made a thing of the past. Training for dental staff might include ways to support patients post-disclosure of their HIV status including: ensuring confidentiality, using non-discriminatory language, booking appointments at any time of day, having up-to-date knowledge of current ART, treatment outcomes for PLHIV and comorbidities likely to affect patients who have been living with HIV for a number of years and who have been on long-term ART. There are also implications for wider engagement of the dental profession, public health and health promotion to reach out to people living with HIV to demonstrate that dental community are listening and changing to ensure they feel and are fully supported in accessing and receiving dental care. Further studies to better the HIV knowledge, perceptions and attitudes of dentists towards people living with HIV would be welcomed in this field.

\section{Conclusion}

In conclusion, this study shows that despite knowledge from the dental and medical profession that HIV is a chronic, manageable disease, stigma toward people living with HIV persists in dental practices. The dental team would benefit from targeted training to improve their ability to support PLHIV when receiving dental 
services and treatment. Targeted under- and post-graduate education in an accessible format such as an e-learning package could support dentists in developing supportive non-discriminatory approaches when working with people living with HIV. The findings highlight that there may be benefit to undertake qualitative research to further explore which behaviours or practices may lead participants to feel stigmatised and discriminated in the dental settings.

\section{Acknowledgement}

FPA would like to thank the UK HIV community, our authors, advisory group members and associate partners: PHE, The National AIDS Trust, HIV Scotland and The All Party Parliamentary Group on HIV/AIDS for their unwavering commitment and support.

\section{Disclosure statement}

No potential conflicts of interest.

\section{Funding statement}

FPA received a grant from the MAC AIDS Fund to deliver The People Living with HIV Stigma Survey UK 2015 with scientific support from

Public Health England and in kind support from The All Party Parliamentary Group on HIV/AIDS. 


\begin{tabular}{|c|c|c|c|c|c|c|c|c|c|}
\hline & \multirow{2}{*}{$\begin{array}{c}\begin{array}{c}\text { Total } \\
(\mathrm{N}=1528)\end{array} \\
\mathrm{n}(\%)\end{array}$} & \multicolumn{2}{|c|}{$\begin{array}{c}\text { Dental staff aware of } \\
\text { HIV status }\end{array}$} & \multicolumn{2}{|c|}{$\begin{array}{l}\text { Worry about being } \\
\text { treated differently }\end{array}$} & \multicolumn{2}{|c|}{$\begin{array}{l}\text { Reported being } \\
\text { treated differently }\end{array}$} & \multicolumn{2}{|c|}{$\begin{array}{c}\text { Felt refused or } \\
\text { significantly delayed }\end{array}$} \\
\hline & & $814(53.3)$ & $P$-value & $610(39.9)$ & $P$-value & $223(14.6)$ & $P$-value & $83(5.4)$ & $P$-value \\
\hline \multicolumn{10}{|l|}{ Demographic } \\
\hline Gender* & & & 0.286 & & 0.193 & & 0.214 & & $<0.001$ \\
\hline Male & $1152(75.4)$ & $627(54.4)$ & & $471(40.9)$ & & $162(14.1)$ & & $58(5.0)$ & \\
\hline Female & $344(22.5)$ & $170(49.4)$ & & $124(36.0)$ & & $54(15.7)$ & & $18(5.2)$ & \\
\hline Transgender or GQNB & $29(1.9)$ & $14(48.3)$ & & $12(41.4)$ & & $7(24.1)$ & & $7(29.2$ & \\
\hline Age group & & & $<0.001$ & & 0.092 & & 0.043 & & 0.601 \\
\hline$<25$ & $36(2.4)$ & $18(50.0)$ & & $13(36.1)$ & & $4(11.1)$ & & $2(5.6)$ & \\
\hline $25-34$ & $229(15.0)$ & $80(34.9)$ & & $94(41.0)$ & & $24(10.5)$ & & $12(5.2)$ & \\
\hline $35-49$ & $734(48.0)$ & $393(53.5)$ & & $319(43.5)$ & & $129(17.6)$ & & $47(6.4)$ & \\
\hline $50-64$ & $409(26.8)$ & $256(62.6)$ & & $147(35.9)$ & & $51(12.5)$ & & $16(3.9)$ & \\
\hline $65+$ & $43(2.8)$ & $34(79.1)$ & & $13(30.2)$ & & $7(16.3)$ & & $2(4.7)$ & \\
\hline Not stated & $77(5.0)$ & $33(42.9)$ & & $24(31.2)$ & & $8(10.4)$ & & $4(5.2)$ & \\
\hline Ethnicity ${ }^{*}$ & & & $<0.001$ & & 0.015 & & 0.740 & & 0.601 \\
\hline White British & $902(59.0)$ & $527(58.4)$ & & $361(40.0)$ & & $125(13.9)$ & & $39(4.3)$ & \\
\hline White Irish & $46(3.0)$ & $23(50.0)$ & & $25(54.3)$ & & $7(15.2)$ & & $3(6.5)$ & \\
\hline Any other white background & $133(8.7)$ & $75(56.4)$ & & $69(51.9)$ & & $24(18.0)$ & & $12(9.0)$ & \\
\hline Black or Black British & $319(20.9)$ & $128(40.1)$ & & $111(34.8)$ & & $48(15.0)$ & & $25(7.8)$ & \\
\hline Asian of Asian British & $24(1.6)$ & 7 (29.2) & & $10(41.7)$ & & $3(12.5)$ & & $1(4.2)$ & \\
\hline Other ethnic groups & $100(6.5)$ & $54(54.0)$ & & $34(34.0)$ & & $16(16.0)$ & & $3(3.0)$ & \\
\hline Sexuality & & & 0.002 & & 0.225 & & 0.139 & & 0.006 \\
\hline MSM & $952(62.3)$ & $534(56.1)$ & & $399(41.9)$ & & $137(14.4)$ & & $47(4.9)$ & \\
\hline Heterosexual men & $184(12.0)$ & $79(42.9)$ & & $64(34.8)$ & & $21(11.4)$ & & $8(4.3)$ & \\
\hline Heterosexual women & $329(21.5)$ & $162(49.2)$ & & $120(36.5)$ & & $51(15.5)$ & & $19(5.8)$ & \\
\hline Other sexuality & $63(4.1)$ & $39(61.9)$ & & $27(42.9)$ & & $14(22.2)$ & & $9(14.3)$ & \\
\hline Ever injecting drug use & & & 0.314 & & 0.05 & & 0.957 & & 0.462 \\
\hline No or Not reported & $1318(86.3)$ & $695(52.7)$ & & $513(38.9)$ & & $192(14.6)$ & & $69(5.2)$ & \\
\hline Yes & $210(13.7)$ & $119(56.7)$ & & $97(46.2)$ & & $31(14.8)$ & & $14(6.7)$ & \\
\hline \multicolumn{10}{|l|}{ SES } \\
\hline Educational level & & & 0.036 & & 0.013 & & 0.825 & & 0.567 \\
\hline
\end{tabular}




\begin{tabular}{|c|c|c|c|c|c|c|c|c|c|}
\hline College or university & $1174(76.8)$ & $617(52.6)$ & & $494(42.1)$ & & $170(14.5)$ & & $60(5.1)$ & \\
\hline Secondary school & $322(21.1)$ & $186(57.8)$ & & $103(32.0)$ & & $50(15.5)$ & & $22(6.8)$ & \\
\hline Up to primary school & $25(1.6)$ & $8(32.0)$ & & $11(44.0)$ & & $2(8.0)$ & & $1(4.0)$ & \\
\hline Not reported & $7(0.5)$ & $3(42.9)$ & & $2(28.6)$ & & $1(14.3)$ & & $0(0.0)$ & \\
\hline Employment status & & & $<0.001$ & & 0.12 & & 0.242 & & 0.189 \\
\hline Full time & $767(50.2)$ & $384(50.1)$ & & $323(42.1)$ & & $102(13.3)$ & & $37(4.8)$ & \\
\hline Part time/casual & $243(15.9)$ & $107(44.0)$ & & $101(41.6)$ & & $36(14.8)$ & & $11(4.5)$ & \\
\hline Retired & $68(4.5)$ & $49(72.1)$ & & $18(26.5)$ & & 7 (10.3) & & $3(4.4)$ & \\
\hline Unemployed & $209(13.7)$ & $117(56.0)$ & & $80(38.3)$ & & $33(15.8)$ & & $17(8.1)$ & \\
\hline Sick or disabled & $135(8.8)$ & $95(70.4)$ & & $54(40.0)$ & & $27(20.0)$ & & $11(8.1)$ & \\
\hline Other & $106(6.9)$ & $62(58.5)$ & & $34(32.1)$ & & $18(17.0)$ & & $4(3.8)$ & \\
\hline Financial commitments & & & 0.247 & & 0.306 & & $<0.001$ & & $<0.001$ \\
\hline Keeping up with bills & $627(41.0)$ & $333(53.1)$ & & $233(37.2)$ & & $62(9.9)$ & & $19(3.0)$ & \\
\hline Struggling with bills & $711(46.5)$ & $376(52.9)$ & & $300(42.2)$ & & $123(17.3)$ & & $42(5.9)$ & \\
\hline Have fallen behind bills & $179(11.7)$ & $82(45.8)$ & & $73(40.8)$ & & $38(21.2)$ & & $21(11.7)$ & \\
\hline Not stated & $11(0.7)$ & $3(27.3)$ & & $4(36.4)$ & & $0(0.0)$ & & $1(9.1)$ & \\
\hline \multicolumn{10}{|l|}{ Health and wellbeing } \\
\hline Year diagnosed & & & $<0.001$ & & 0.376 & & 0.288 & & 0.221 \\
\hline In the last year & $121(7.9)$ & $29(24.0)$ & & $53(43.8)$ & & $13(10.7)$ & & $1(0.8)$ & \\
\hline $2010-2013$ & $360(23.6)$ & $158(43.9)$ & & $158(43.9)$ & & $45(12.5)$ & & $21(5.8)$ & \\
\hline $2005-2009$ & $388(25.4)$ & $199(51.3)$ & & $160(41.2)$ & & $62(16.0)$ & & $25(6.4)$ & \\
\hline $2000-2004$ & $297(19.4)$ & $171(57.6)$ & & $110(37.0)$ & & $41(13.8)$ & & $18(6.1)$ & \\
\hline$<2000$ & $343(22.4)$ & $253(73.8)$ & & $123(35.9)$ & & $60(17.5)$ & & $17(5.0)$ & \\
\hline Not stated & $19(1.2)$ & $4(21.1)$ & & $6(31.6)$ & & $2(10.5)$ & & $1(5.3)$ & \\
\hline On ART & & & $<0.001$ & & 0.216 & & 0.621 & & 0.742 \\
\hline Yes & $1411(92.3)$ & $776(55.0)$ & & $559(39.6)$ & & $208(14.7)$ & & $76(5.4)$ & \\
\hline No & $110(7.2)$ & 37 (33.6) & & $51(46.4)$ & & $15(13.6)$ & & $7(6.4)$ & \\
\hline Not stated & $7(0.5)$ & $1(14.3)$ & & $1(14.3)$ & & $0(0.0)$ & & $0(0.0)$ & \\
\hline Poor self-image & & & 0.012 & & $<0.001$ & & $<0.001$ & & 0.096 \\
\hline No & $972(63.6)$ & $542(55.8)$ & & $325(33.4)$ & & $112(11.5)$ & & $46(4.7)$ & \\
\hline Yes & $556(36.4)$ & 272 (48.9) & & $285(51.3)$ & & $111(20.0)$ & & 37 (6.7) & \\
\hline
\end{tabular}

$245 \quad P$-value, Chi(2) $P$-value,

246 *Missing value below 5 are not indicated in the table 
Table 2. Descriptive, univariate and multivariate analyses of avoidance of dental care in the previous 12 months among people living with HIV in the UK

\begin{tabular}{|c|c|c|c|c|c|c|c|}
\hline \multirow[b]{2}{*}{$n(\%)$} & \multicolumn{2}{|l|}{ N (\%) } & \multicolumn{2}{|c|}{ Univariate model } & \multicolumn{2}{|c|}{ Multivariate model ${ }^{*}$} & \multirow[b]{2}{*}{$\boldsymbol{P}$} \\
\hline & $217(14.2)$ & OR & $95 \% \mathrm{Cl}$ & $P$ & aOR & $95 \% \mathrm{Cl}$ & \\
\hline \multicolumn{8}{|l|}{ Demographic } \\
\hline Gender & & & & 0.049 & & & \\
\hline Male & $156(13.5)$ & 1 & & & & & \\
\hline Female & $53(15.4)$ & 1.2 & $(0.86-1.69)$ & & & & \\
\hline Transgender or GQNB & $7(29.2)$ & 2.46 & $(1.00-6.03)$ & & & & \\
\hline Age group & & & & 0.046 & & & \\
\hline$<25$ & $7(19.4)$ & 1.27 & $(0.54-2.98)$ & & & & \\
\hline $25-34$ & $34(14.8)$ & 0.86 & $(0.57-1.30)$ & & & & \\
\hline $35-49$ & $121(16.5)$ & 1 & & & & & \\
\hline $50-64$ & $43(10.5)$ & 0.58 & $(0.40-0.84)$ & & & & \\
\hline $65+$ & $3(7.0)$ & 0.39 & $(0.12-1.29)$ & & & & \\
\hline Not stated & $9(11.7)$ & 0.86 & $(0.41-1.81)$ & & & & \\
\hline Ethnicity & & & & 0.98 & & & \\
\hline White British & $132(14.6)$ & 1 & & & & & \\
\hline White Irish & $5(10.9)$ & 0.68 & $(0.26-1.74)$ & & & & \\
\hline Any other white background & $18(13.5)$ & 0.96 & $(0.56-1.64)$ & & & & \\
\hline Black or Black British & $45(14.1)$ & 1.01 & $(0.70-1.47)$ & & & & \\
\hline Asian of Asian British & $3(12.5)$ & 0.98 & $(0.28-3.31)$ & & & & \\
\hline Other ethnic groups & $14(14.0)$ & 1.06 & $(0.58-1.94)$ & & & & \\
\hline Sexuality & & & & 0.469 & & & \\
\hline MSM & $134(14.1)$ & 1 & & & & & \\
\hline Heterosexual men & $21(11.4)$ & 0.81 & $(0.50-1.33)$ & & & & \\
\hline Heterosexual women & $52(15.8)$ & 1.21 & $(0.85-1.71)$ & & & & \\
\hline Other sexuality & $10(15.9)$ & 1.25 & $(0.62-2.54)$ & & & & \\
\hline Ever injecting drug use & & & & 0.578 & & & \\
\hline No or Not reported & $189(14.3)$ & 1 & & & & & \\
\hline Yes & $28(13.3)$ & 0.89 & $(0.58-1.36)$ & & & & \\
\hline \multicolumn{8}{|l|}{ SES } \\
\hline Educational level & & & & 0.972 & & & \\
\hline College or university & $169(14.4)$ & 1 & & & & & \\
\hline Secondary school & $45(14.0)$ & 0.98 & $(0.69-1.40)$ & & & & \\
\hline Up to primary school & $3(12.0)$ & 0.87 & $(0.26-2.98)$ & & & & \\
\hline Employment status & & & & 0.209 & & & \\
\hline Full time & $108(14.1)$ & 1 & & & & & \\
\hline Part time/casual & $36(14.8)$ & 1.06 & $(0.70-1.59)$ & & & & \\
\hline Retired & $3(4.4)$ & 0.3 & $(0.09-0.98)$ & & & & \\
\hline Unemployed & $30(14.4)$ & 1.08 & $(0.70-1.68)$ & & & & \\
\hline Sick or disabled & $26(19.3)$ & 1.47 & $(0.91-2.37)$ & & & & \\
\hline Other & $14(13.2)$ & 0.95 & $(0.52-1.74)$ & & & & \\
\hline Financial commitments & & & & 0.002 & & & 0.297 \\
\hline Keeping up with bills & 65 (10.4) & 0.59 & $(0.43-0.82)$ & & 0.68 & $(0.45-1.03)$ & \\
\hline Struggling with bills & $116(16.3)$ & 1 & & & 1 & & \\
\hline Have fallen behind bills & 35 (19.6) & 1.29 & $(0.84-1.96)$ & & 0.79 & $(0.45-1.39)$ & \\
\hline Not stated & $1(9.1)$ & 0.8 & $(0.09-6.67)$ & & 1.31 & $(0.12-14.7)$ & \\
\hline Health and wellbeing & & & & & & & \\
\hline
\end{tabular}




\begin{tabular}{|c|c|c|c|c|c|c|c|}
\hline Year diagnosed & & & & 0.372 & & & \\
\hline In the last year & $21(17.4)$ & 1.09 & $(0.63-1.88)$ & & & & \\
\hline $2010-2013$ & $58(16.1)$ & 1.02 & $(0.69-1.51)$ & & & & \\
\hline 2005-2009 & $61(15.7)$ & 1 & & & & & \\
\hline 2000-2004 & $35(11.8)$ & 0.74 & $(0.47-1.15)$ & & & & \\
\hline$<2000$ & $41(12.0)$ & 0.72 & $(0.47-1.11)$ & & & & \\
\hline Not stated & $1(5.3)$ & 0.45 & $0.06-3.57)$ & & & & \\
\hline On ART & & & & 0.154 & & & \\
\hline Yes & $197(14.0)$ & 1 & & & & & \\
\hline No & $20(18.2)$ & 0.69 & $(0.41-1.15)$ & & & & \\
\hline Poor self-image & & & & $<0.001$ & & & 0.008 \\
\hline No & $100(10.3)$ & 1 & & & 1 & & \\
\hline Yes & $117(21.0)$ & 2.7 & $(1.77-3.18)$ & & 1.65 & $(1.14-2.40)$ & \\
\hline $\begin{array}{l}\text { Experiences in relation to HIV } \\
\text { status }\end{array}$ & & & & & & & \\
\hline $\begin{array}{l}\text { Dental staff aware of HIV } \\
\text { status }\end{array}$ & & & & 0.743 & & & \\
\hline Yes & $113(13.9)$ & 1 & & & & & \\
\hline No & $103(14.5)$ & 0.92 & $(0.69-1.23)$ & & & & \\
\hline Not reported & $1(20.0)$ & 1.79 & $(0.18-17.4)$ & & & & \\
\hline $\begin{array}{l}\text { Felt supported upon } \\
\text { disclosure }\end{array}$ & & & & $<0.001$ & & & 0.142 \\
\hline $\begin{array}{l}\text { Dental staff not aware of HIV } \\
\text { status }\end{array}$ & $104(14.6)$ & 1 & & & 1 & & \\
\hline $\begin{array}{l}\text { Felt not supported upon } \\
\text { disclosure }\end{array}$ & $68(25.5)$ & 1.98 & $(1.4-2.8)$ & & 1.46 & $(0.89-2.30)$ & \\
\hline Felt supported upon disclosure & $41(8.1)$ & 0.5 & $(0.34-0.73)$ & & 0.85 & $(0.49-1.48)$ & \\
\hline Not reported & $4(10.0)$ & 0.72 & $(0.25-2.08)$ & & 1.44 & $(0.34-6.08)$ & \\
\hline $\begin{array}{l}\text { Worry about being treated } \\
\text { differently }\end{array}$ & & & & $<0.001$ & & & $<0.001$ \\
\hline No & $34(3.6)$ & 1 & & & & & \\
\hline Yes & $182(35.7)$ & 15.11 & (10.3-22.3) & & 7.52 & $(4.8-11.8)$ & \\
\hline Not reported & $1(1.3)$ & 13.16 & $(1.16-149)$ & & 0.13 & $(0.004-4.2)$ & \\
\hline $\begin{array}{l}\text { Reported being treated } \\
\text { differently }\end{array}$ & & & & $<0.001$ & & & $<0.001$ \\
\hline No & $100(8.3)$ & 1 & & & 1 & & \\
\hline Yes & $233(49.8)$ & 11.33 & $(8.10-15.8)$ & & 2.89 & $(1.86-4.47)$ & \\
\hline Not reported & $6(6.4)$ & 16.53 & $(4.59-54.6)$ & & 13.91 & $(0.87-221)$ & \\
\hline $\begin{array}{l}\text { Felt refused or significantly } \\
\text { delayed care }\end{array}$ & & & & $<0.001$ & & & $<0.001$ \\
\hline No & $151(11.3)$ & 1 & & & 1 & & \\
\hline Yes & $60(72.3)$ & 20.51 & $(12.3-34.1)$ & & 6.41 & $(3.44-11.9)$ & \\
\hline Not reported & $6(5.7)$ & 11.79 & $(3.29-42.3)$ & & 8.63 & $(0.70-107)$ & \\
\hline
\end{tabular}

${ }^{*}$ Adjusting for year of diagnosis as an a priori factor, gender, age, employment status.

OR, odds ratio; aOR, adjusted odds ratio; $\mathrm{Cl}$, confidence interval, $P, \mathrm{Chi}(2) P$-value. 


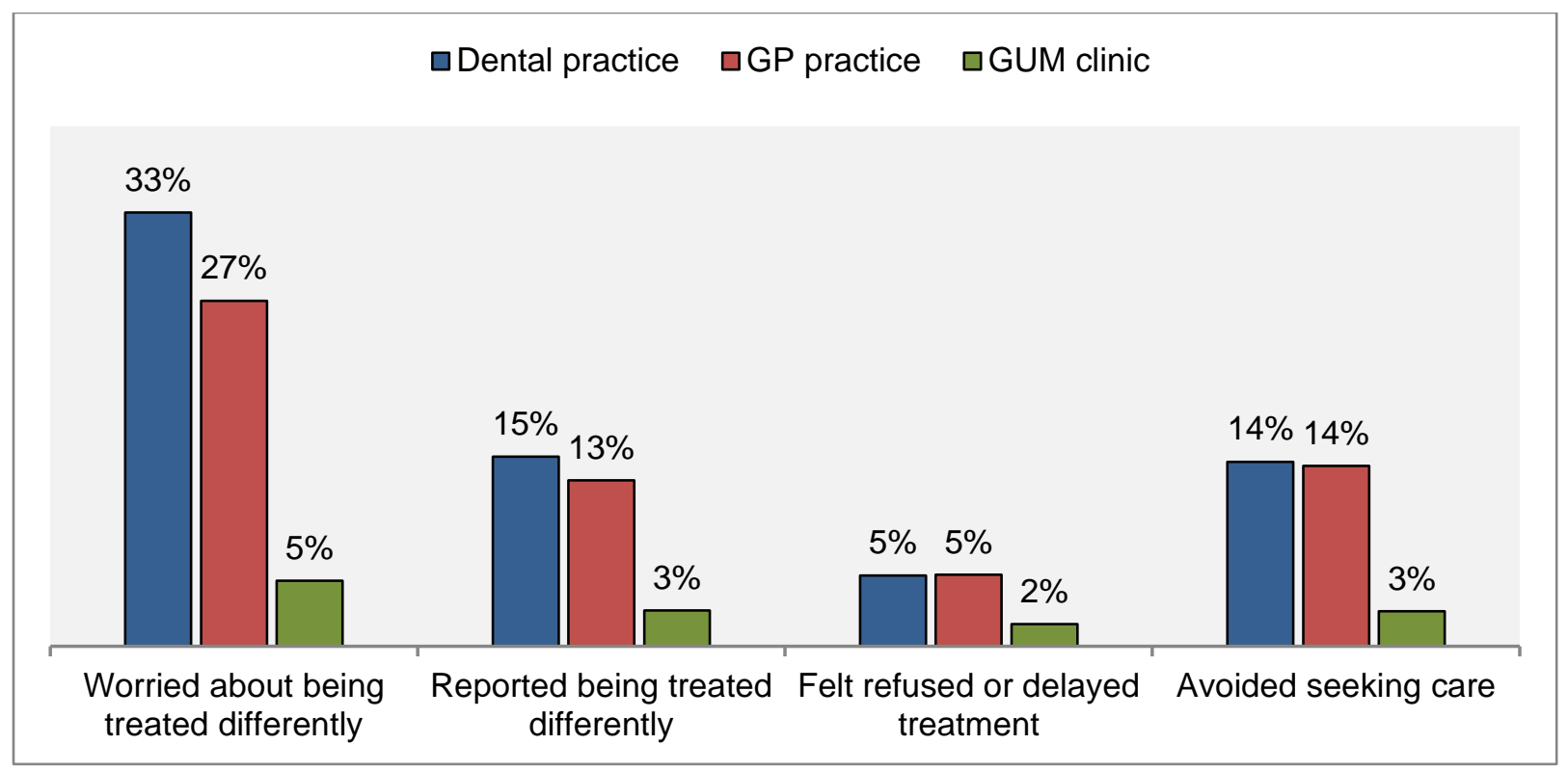

Figure 1. Stigma and discrimination experiences of people living with HIV in the previous 12 months in dental practice and other healthcare settings. Histogram presenting the experiences of stigma and discrimination of people living with HIV in dental practices, general practitioners (GP) practices and genitourinary medicine $(\mathrm{GUM})$ clinic $(\mathrm{N}=1528)$. Percentages presented include missing values (all $<7 \%$ ). 


\section{References}

1. Burger-Calderon R, Smith JS, Ramsey KJ, et al. The Association between the History of HIV Diagnosis and Oral Health. J Dent Res 2016;95(12):1366-74. doi:

10.1177/0022034516661518 [published Online First: 2016/08/17]

2. Dobalian A, Andersen RM, Stein JA, et al. The impact of HIV on oral health and subsequent use of dental services. J Public Health Dent 2003;63(2):78-85. [published Online First: 2003/06/21]

3. Soares GB, Garbin CAS, Rovida TAS, et al. Oral health associated with quality of life of people living with HIV/AIDS in Brazil. Health Qual Life Outcomes 2014;12:28. doi: 10.1186/1477-7525-12-28

4. Benjamin RM. Oral Health Care for People Living with HIV/AIDS. Public Health Rep 2012;127(Suppl 2):1-2.

5. Rajabiun S, Fox JE, McCluskey A, et al. Patient Perspectives on Improving Oral Health-Care Practices Among People Living with HIV/AIDS. Public Health Rep 2012;127(Suppl 2):73-81.

6. Santella AJ, Conway DI, Watt RG. The potential role of dentists in HIV screening. British Dental Journal 2016;220(5):229-33. doi: doi:10.1038/sj.bdj.2016.172

7. Deeks SG, Lewin SR, Havlir DV. The End of AIDS: HIV Infection as a Chronic Disease. Lancet 2013;382(9903):1525-33. doi: 10.1016/s0140-6736(13)61809-7

8. May MT, Gompels M, Delpech V, et al. Impact on life expectancy of HIV-1 positive individuals of CD4+ cell count and viral load response to antiretroviral therapy. Aids 2014;28(8):1193-202. doi: 10.1097/qad.0000000000000243 [published Online First: 2014/02/22]

9. Kirwan, P.D., et al., HIV in the UK - 2016 report. December 2016. . 2016, Public Health England, London:

https://www.gov.uk/government/uploads/system/uploads/attachment data/file/57 4667/HIV in the UK 2016.pdf.

10. Rueda S, Mitra S, Chen S, et al. Examining the associations between HIV-related stigma and health outcomes in people living with HIV/AIDS: a series of meta-analyses. 2016 doi: 10.1136/bmjopen-2016-011453

11. Patel N, Furin JJ, Willenberg DJ, et al. HIV-related Stigma in the Dental Setting: A Qualitative Study. Spec Care Dentist 2015;35(1):22-8. doi: 10.1111/scd.12078

12. Mahajan AP, Sayles JN, Patel VA, et al. Stigma in the HIV/AIDS epidemic: A review of the literature and recommendations for the way forward. AIDS 2008;22(Suppl 2):S67-79. doi: 10.1097/01.aids.0000327438.13291.62

13. Goffman E. Stigma: Notes On The Management Of Spoiled Identity: Penguin 1963.

14. Pulerwitz J, Michaelis A, Weiss E, et al. Reducing HIV-Related Stigma: Lessons Learned from Horizons Research and Programs. Public Health Rep 2010;125(2):272-81.

15. Ekstrand ML, Ramakrishna J, Bharat $S$, et al. Prevalence and drivers of HIV stigma among health providers in urban India: implications for interventions. J Int AIDS Soc 2013;16(3Suppl 2) doi: 10.7448/ias.16.3.18717

16. Shiboski $\mathrm{CH}$, Cohen $\mathrm{M}$, Weber $\mathrm{K}$, et al. Factors associated with use of dental services among HIV-infected and high-risk uninfected women. J Am Dent Assoc 2005;136(9):1242-55. [published Online First: 2005/10/04] 
17. Levett T, Slide C, Mallick F, et al. Access to dental care for HIV patients: does it matter and does discrimination exist? Int J STD AIDS 2009;20(11):782-4. doi: 10.1258/ijsa.2009.009182 [published Online First: 2009/10/31]

18. McGoldrick C. HIV and employment. Occup Med (Lond) 2012;62(4):242-53. doi: 10.1093/occmed/kqs051 [published Online First: 2012/06/05]

19. Williams M. The HIV positive dentist in the United Kingdom--a legal perspective. Br Dent J 2009;207(2):77-81. doi: 10.1038/sj.bdj.2009.608 [published Online First: 2009/07/25]

20. Elford J, Ibrahim F, Bukutu C, et al. HIV-related discrimination reported by people living with HIV in London, UK. AIDS Behav 2008;12(2):255-64. doi: 10.1007/s10461-0079344-2 [published Online First: 2007/12/18]

21. Beck AT, Epstein N, Brown G, et al. An inventory for measuring clinical anxiety: psychometric properties. J Consult Clin Psychol 1988;56(6):893-7. [published Online First: 1988/12/01]

22. Reznik DA. Oral manifestations of HIV disease. Top HIV Med 2005;13(5):143-8. [published Online First: 2005/12/27]

23. Arnold EA, Rebchook GM, Kegeles SM. "Triply cursed": Racism, homophobia, and HIVrelated stigma are barriers to regular HIV testing, treatment adherence, and disclosure among young Black gay men. Cult Health Sex 2014;16(6):710-22. doi: 10.1080/13691058.2014.905706

24. Feyissa GT, Abebe L, Girma E, et al. Stigma and discrimination against people living with HIV by healthcare providers, Southwest Ethiopia. BMC Public Health 2012;12:522. doi: 10.1186/1471-2458-12-522 [published Online First: 2012/07/17]

25. Croser D. Written off. British Dental Journal 2006;201(8):497-99. doi: doi:10.1038/sj.bdj.4814168

26. NHS. Standard Infection Control Precautions, 2010.

27. Sharp L. The People Living with HIV Stigma Index Qualitative Data: Findings of the qualitative work undetaken to complement the people living with HIV stigma index. 2010.

http://www.stigmaindexuk.org/reports/final qualitative report nov 2010.pdf?

28. Avery CME, Gallagher P, Birnbaum W. cross-infection control: Double gloving and a glove perforation indication system during the dental treatment of HIV-positive patients: are they necessary? British Dental Journal 1999;186(1):27-29. doi: doi:10.1038/sj.bdj.4800009 


\section{Supplementary information}

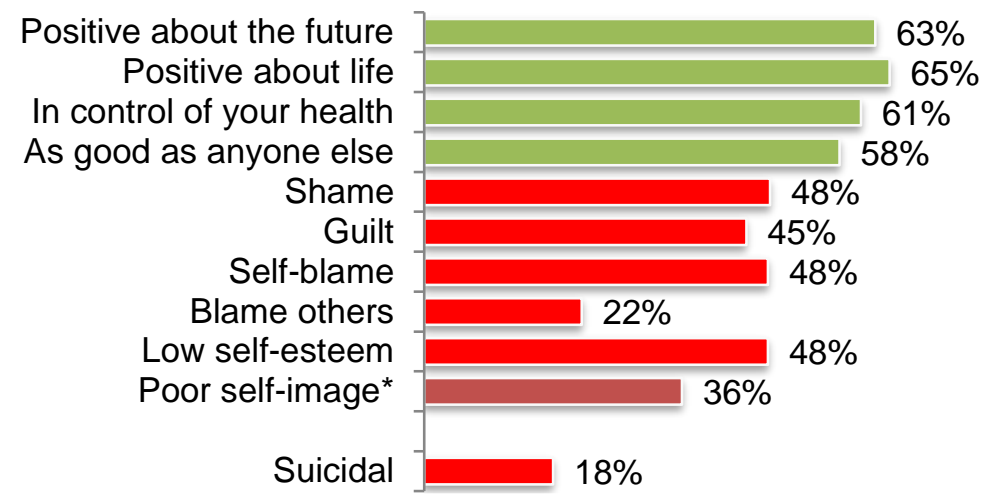

Figure 1. Assessment of people living with HIV self-image in relation to their HIV status. Participants were asked ten questions about positive and negative feelings in relation to their HIV status in the last 12 months $(\mathrm{N}=1528)$. Poor self-image* was assessed using a scoring system with a "yes" answer giving a value of -1 , a "no" of 0 , and a "not sure" of -0.5 . Scores generated ranged from -4 to 6 and a mid-point score of 1 or above was used to indicate a poor self-image. 